\title{
Cicatrizadores personalizados: Una opción para conformación del perfil de emergencia en prótesis sobre implantes posteriores
}

\author{
Customized healing abutments: An option for emergence profile conformation in posterior implants \\ prosthesis
}

\author{
Lizzeth Fiorella Huaytalla Oré1,a,e, Carlos Matta Morales 2 2,a,b,c,d
}

\section{RESUMEN}

La pérdida de piezas dentales trae como consecuencia el colapso a nivel de su tejido de soporte circundante, lo que desarrolla una deformidad del reborde. Asimismo los tejidos blandos sufren modificaciones en su estructura que en muchos casos podrían resultar complicadas de restablecer. Cuando se realiza la planificación de cirugía de implantes, no solo debemos enfocarnos en sustituir las piezas dentarias propiamente dichas también debemos lograr un resultado estético y funcional, que en la medida de lo posible se asemeje mucho a la anatomía natural del diente. La conformación de papilas y manejo de tejido blando periimplantario es un desafío que en la actualidad tiene diversas alternativas de tratamiento. El objetivo de este artículo es proporcionar una técnica alternativa para la conformación del perfil de emergencia en prótesis con soporte de implantes en las que se utilizará el método de compresión, mediante el uso de un tornillo de cicatrización personalizado con adición de resina para conformar el tejido periimplantario de los dientes posteriores.

PALABRAS CLAVE: Implantes dentales, prótesis dental, prótesis e implantes, tejidos.

\section{SUMMARY}

Tooth losing results in a collapse of their supporting tissues, which develops a ridge deformity. Soft tissues also undergo modifications in their structure, which in many cases could be difficult to restore. When implant surgery planning is carried out, we should not only we focus on replacing the dental pieces themselves, but we should also achieve an aesthetic and functional result that, to the extent possible, closely resembles the

\footnotetext{
Programa de posgrado en Rehabilitación Oral, Facultad de Estomatología Roberto Beltrán, Universidad Peruana Cayetano Heredia. Lima, Perú.

Departamento Académico de la Clínica Estomatológica, Facultad de Estomatología, Universidad Peruana Cayetano Heredia. Lima, Perú. 
natural tooth anatomy. The papillae conformation and the peri-implant soft tissue management is a challenge that currently has several treatment alternatives. The aim of this article is to provide an alternative technique for emergency profile conformation on implant-supported prostheses in which the compression method will be used, by using a customized healing screw with resin addition in order to conform the posterior teeth peri-implantar tissue.

KEYWORDS: Dental implants, dental prosthesis, prostheses and implants, tissues.

\section{INTRODUCCIÓN}

Actualmente en prótesis sobre implantes el manejo de los tejidos blandos periimplantarios demandará siempre un reto, sobretodo si se trata de reemplazar estructuras que se encuentran en zonas visibles en las que la demanda estética es alta, debido a que se busca una gran aproximación a lo natural.

En un intento por imitar lo natural, la rehabilitación sobre implantes en conjunto con el manejo de los tejidos periimplantarios nos presenta diferentes opciones que envuelven desde tratamientos a través de injertos de tejido duro y/o blando hasta la simulación gingival mediante infraestructuras metálicas recubiertas con acrílico rosado. Una opción valida es también el manejo de los tejidos blandos periimplantarios ejerciendo compresión radial de manera que el contorno se conforma de manera gradual y uniforme alrededor de la corona sobre implante.

El objetivo del presente trabajo es dar a conocer una alternativa de conformación de perfil de emergencia en prótesis sobre implantes en la cual se utilizará el método de compresión gradual utilizando el tornillo de cicatrización con agregado de resina para la conformación del tejido periimplantario en piezas dentales posteriores. Esta técnica de manejo de tejidos blandos surge como alternativa a la utilización de coronas provisionales sobre implantes y permite también realizar posteriormente una impresión con transferente personalizado al finalizar la etapa de conformación. Sin embargo, para situarnos en contexto iniciaremos presentando brevemente las fases que conforman la técnica de Rehabilitación de Prótesis sobre Implantes.

\section{Primera fase quirúrgica}

Se trata de la colocación de los implantes en el lecho alveolar.

El protocolo quirúrgico propuesto por Branemark determina el fundamento de la cirugía implantar de oseointegración. Tales preceptos tienen por objeto lograr las mejores condiciones biológicas para favorecer la oseointegración del implante. Durante la preparación del lecho óseo receptor, se utilizan fresas de diámetro ascendente bajo constante irrigación, para prevenir el detrimento óseo provocado por sobrecalentamiento (1).

La secuencia de los eventos de cicatrización que lideran la oseointegración no fueron dilucidados hasta que se publicaron los resultados de un estudio en animales (2). La oseointegración fue estudiada en un periodo de tiempo de 2 horas a 12 semanas posteriores a la colocación del implante. Los eventos que preceden la oseointegración son: formación del coágulo, formación de tejido de granulación, desarrollo de matriz provisional, formación de hueso que inicia su organización (woven), formación de hueso con fibras paralelas y eventualmente formación de hueso lamelar (3).

La morfogénesis de los tejidos blandos de la unión mucosa - implante fue dilucidada usando el mismo modelo animal que se usó en la oseointegración (4). Los primeros signos de proliferación epitelial fueron observados en la primera y segunda semana de cicatrización estableciéndose una barrera epitelial pero con reducida altura. A las dos semanas de cicatrización, se observa una gran cantidad de fibroblastos que predominan en la interface del tejido conectivo. Más adelante, a las 4 semanas, la densidad de fibroblastos disminuye sustancialmente. Después de 6 - 8 semanas de cicatrización, un epitelio de barrera maduro, totalmente desarrollado en términos de tamaño se establece. Las fibras colágenas de la mucosa se organizan después de 4 - 6 semanas. Después de este periodo de observación, ni las dimensiones del sellado implante-mucosa ni el contenido de los componentes 
del tejido en esta área cambian. Sin embargo se debe asumir que el sellado mucosa-implante es totalmente funcional y establecido después de las 6 - 8 semanas de haber sido insertado el implante (5).

\section{Segunda fase quirúrgica}

Una vez colocado el implante se espera el proceso de oseointegración para proceder a la segunda fase. En esta etapa se realiza el descubrimiento del implante, colocándose un cicatrizador, el cual servirá de componente itinerante entre la exposición del implante y la futura rehabilitación protésica sobre el mismo.

\section{Selección de cicatrizador}

La mucosa periimplantaria consiste en un epitelio de barrera de 2-mm de largo y 1-1.5 mm de "tejido conectivo integrado”. El tejido blando, incluyendo un epitelio de unión tiene una longitud en sentido apico-coronal de $2 \mathrm{~mm}$ y se encuentra separado de la cresta ósea por una zona de tejido conectivo de unión de $1 \mathrm{~mm}$ de longitud. La mayoría de fibras alrededor del implante se encuentran aparentemente ancladas al periostio de la cresta ósea $(6,7)$. Los cicatrizadores guían la conformación de los tejidos blandos después de la colocación del implante en una situación de protocolos quirúrgicos de una sola fase, o después del descubrimiento del implante en un protocolo quirúrgico de dos fases (8). Estos aditamentos se seleccionan de acuerdo al espesor de mucosa y el diámetro de acuerdo a la pieza que será reemplazada con la rehabilitación protésica. En la selección de los cicatrizadores se estudia el espacio protésico tridimensional y el espesor de la mucosa. Debido a que el cicatrizador debería tener el mismo diseño de los pilares o intermediarios en la porción subgingival, es importante que éste sea seleccionado de acuerdo con la altura del tejido gingival y también con el mismo diámetro del pilar que será posteriormente utilizado. El área cóncava ofrecerá condiciones para crecimiento tisular y la elección del pilar deberá respetar el contorno formado por el cicatrizador. Si la región requiere más seguridad en relación al espacio subgingival, el pilar podrá ser elegido con un cuff más bajo, sin embargo, se debe proceder a la anestesia previa, instalar el pilar y aguardar a que el tejido se acomode adecuadamente para proceder a aplicar el torque, ya que esto podría causar molestia (9).
Dependiendo del sistema de implantes, podremos encontrar cicatrizadores con sección transversal circular, los cuales crearán una arquitectura gingival con esta conformación la cual no trae como resultado una restauración estética (10). También podemos encontrar cicatrizadores con conformación divergente, sin embargo en algunos otros sistemas de implantes podremos solo encontrar cicatrizadores con forma paralela que no nos bridarán una conformación adecuada. Por lo cual, en estos casos, un cicatrizador personalizado es mandatorio para crear una arquitectura gingival óptima (10).

\section{Conformación de perfil con restauración provisional}

Las restauraciones provisionales sobre implantes son comúnmente usadas en la zona estética.

Este tipo de restauraciones son ideales debido a que permiten conformar secuencialmente los tejidos blandos con los perfiles adecuados y con la presencia de una restauración lo más parecido posible a lo que en un futuro vendría a ser nuestra restauración definitiva.

Esta restauración provisional se proporciona para crear y acondicionar los contornos de los tejidos blandos periimplantarios, reproduciendo así la apariencia fisiológica, festoneada, parabólica y el tropismo de la encía adyacente. La prótesis provisional de resina se mantiene en la cavidad oral durante un período de 3 a 6 meses para garantizar un resultado estable del acondicionamiento de los tejidos blandos periimplantarios (11).

Desde un punto de vista de secuencia de tratamiento, una restauración provisional puede ser colocada inmediatamente después de la cirugía de implantes o en un protocolo diferido, después de un adecuado tiempo de cicatrización. . tras 4 semanas de incremento progresivo de resina los di, diversos diseños y tr el tejido blando con los perfiles adecuados yLas provisionales pueden ser elaboradas en numerosas formas, diversos diseños y técnicas de producción (12). Son en su mayoría utilizados para técnicas de implantes inmediatos post exodoncia, principalmente en el sector anterior o estético. 


\section{Conformación de perfil con cicatrizador personalizado}

\section{Técnica de elaboración del cicatrizador personalizado}

Se bloquea con resina de obturación temporal la chimenea del tornillo correspondiente al pilar de cicatrización, con la finalidad de evitar que ingrese material de obturación definitivo que será utilizado para la conformación alrededor del pilar de cicatrización (figuras 1, 2 y 3) .

En una platina de vidrio colocar resina fluida formando un domo (figura 4).

Sobre el domo formado con resina fluida sumergir el pilar de cicatrización previamente arenado y conformar los contornos con una espátula de resina (figuras 5 y 6 ).

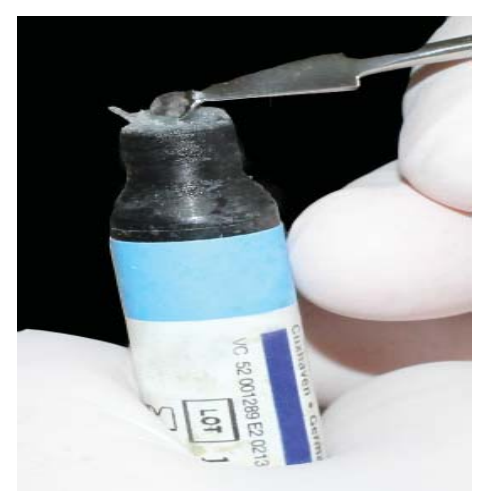

Figura 1. Resina de obturación temporal.

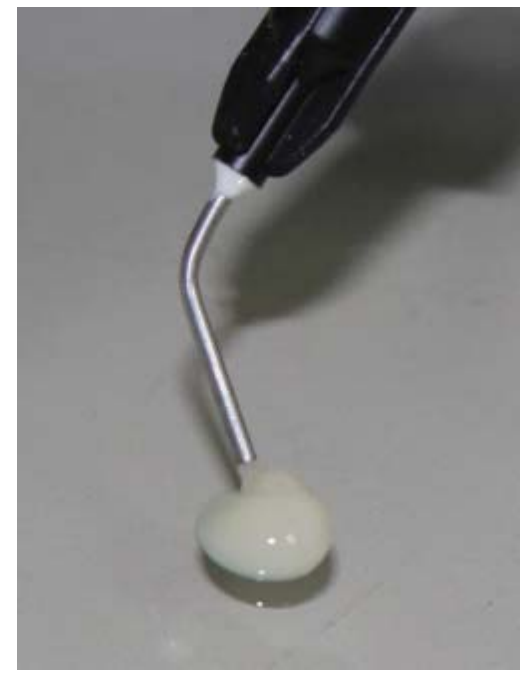

Figura 4. Domo de resina fluida

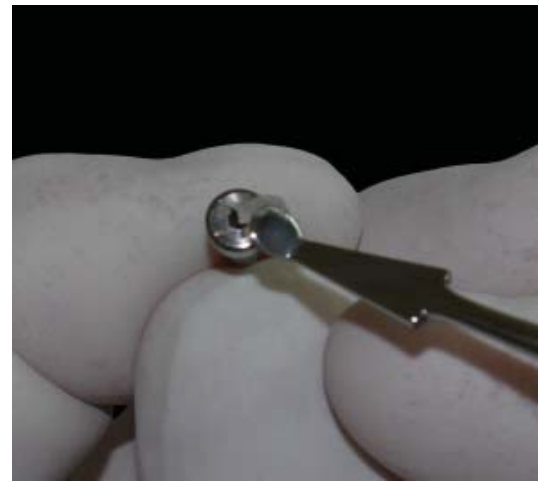

Figura 2. Bloquear la chimenea del tornillo del pilar de cicatrización

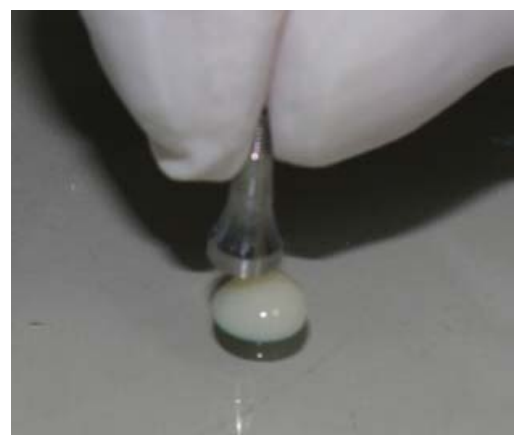

Figura 5. Sumergir pilar de cicatrización en domo de resina

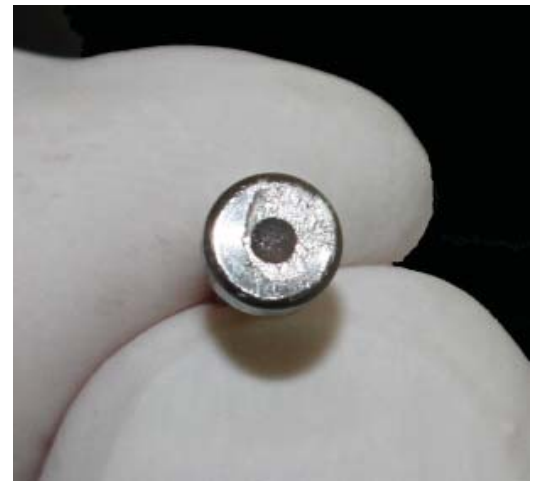

Figura 3. Chimenea del tornillo bloqueada.

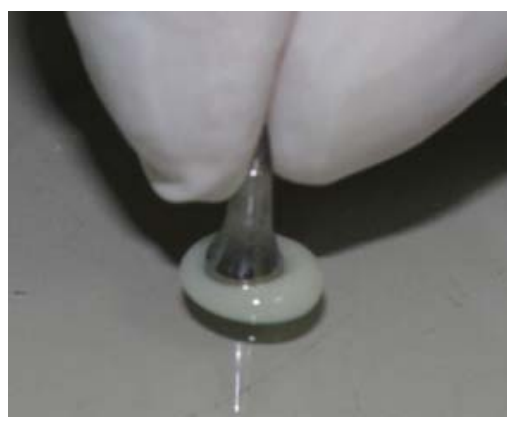

Figura 6. Conformar contornos con espátula de resina. 


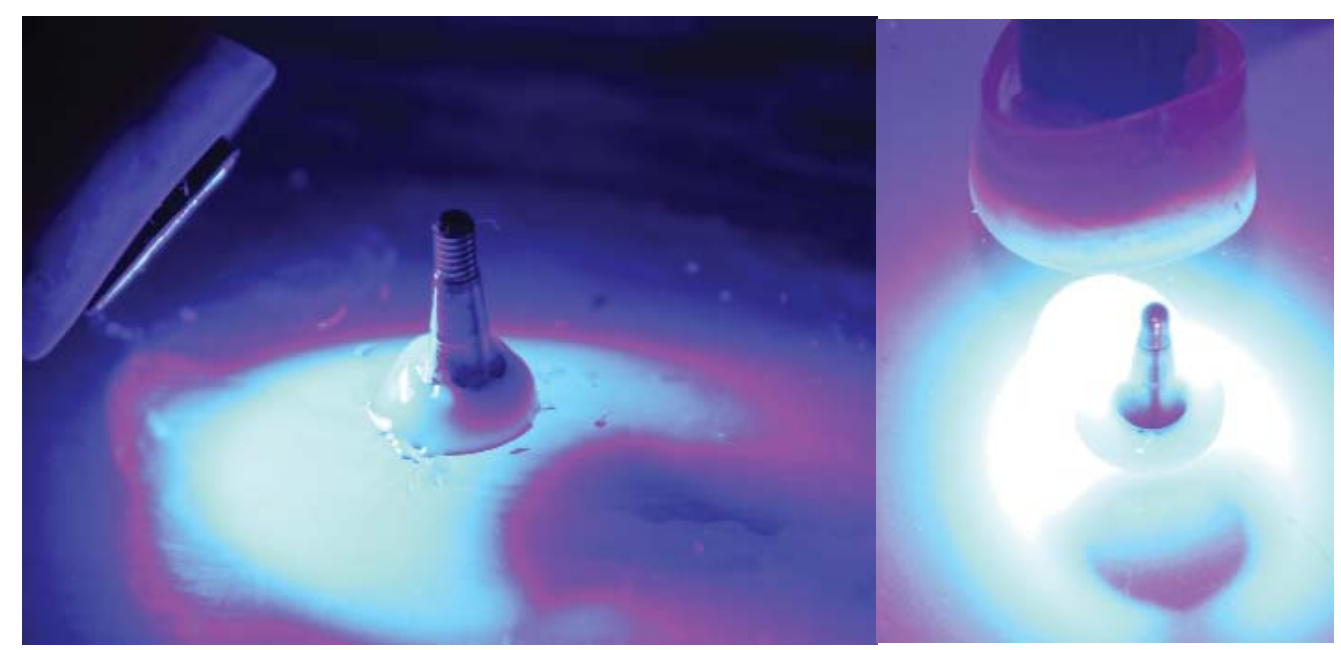

Figura 7. Fotopolimerización de agregados de resina.

Una vez conformados los contornos alrededor del cicatrizador proceder a fotopolimerizar por todas las superficies (figura 7).

Posteriormente a la polimerización del material, se obtendrá un pilar de cicatrización con un halo de resina amplio (figura 8) el cual deberá ser conformado de acuerdo al contorno de la pieza que se requiere reemplazar tomando en cuenta siempre que las mucosas se someterán a compresión continua de manera incremental.

Con la ayuda de discos soflex, realizar el desgaste y contornear el halo alrededor del pilar de cicatrización hasta obtener el diámetro adecuado, asimismo realizar un prolijo pulido de la superficie que entrará en contacto con la mucosa periimplantaria (figura 9).

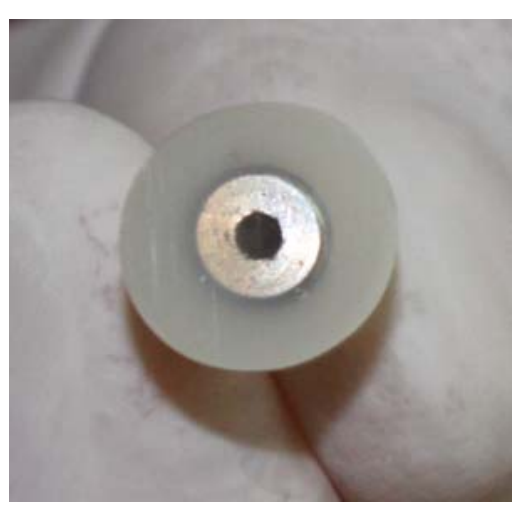

Figura 8. Halo inicial de resina fotopolimerizada.
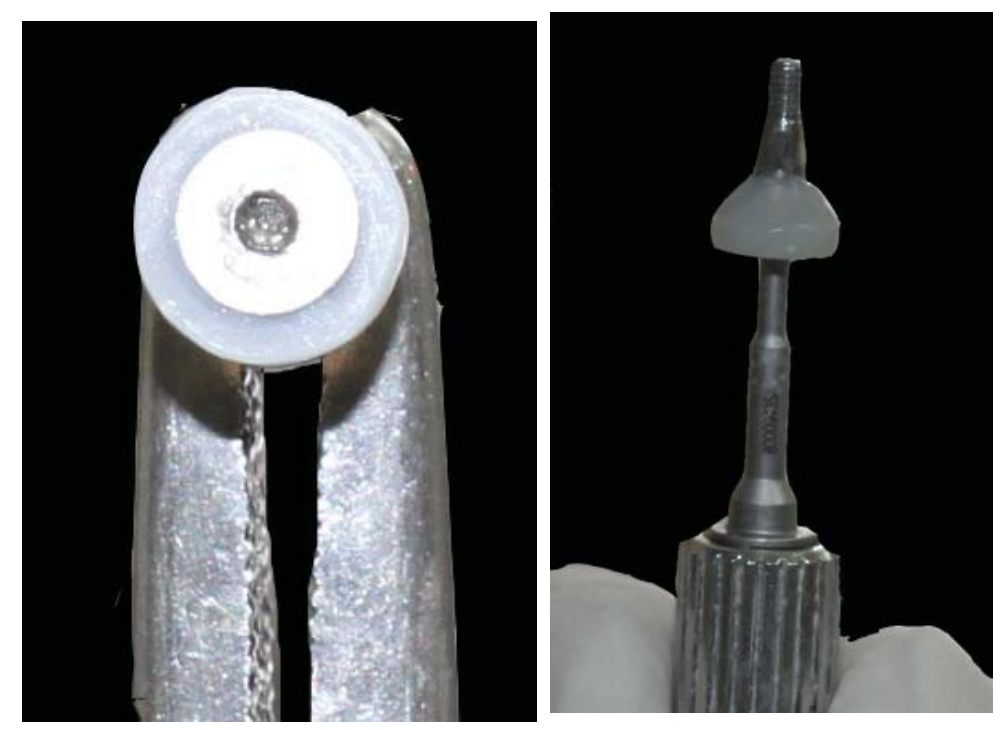

Figura 9. Conformación y reducción con discos soflex de halo de resina alrededor de cicatrizador . 
Una vez obtenidos los diámetros adecuados proceder a atornillar los pilares de cicatrización sobre los implantes (figura 10).

Se realizan los controles respectivos posteriores a los incrementos graduales de resina, en los cuales se observa la conformación adecuada hasta lograr los resultados deseados (figura 11).
Una vez que se logra la morfología gingival, se llevarán a cabo los procedimientos para la confección de provisionales, la transferencia personalizada y posteriormente la confección de la restauración definitiva (figura 12).

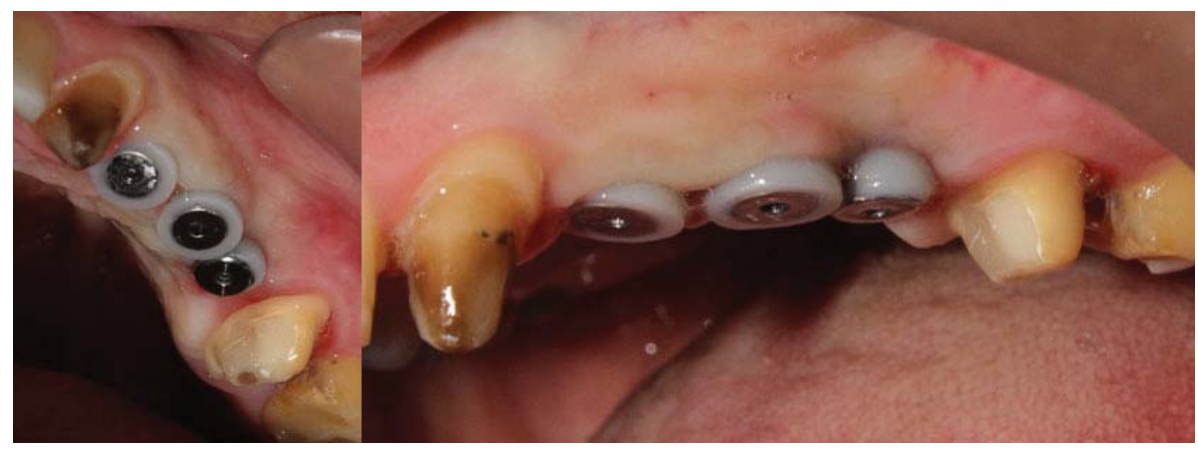

Figura 10. Pilares de cicatrización atornillados con resina para conformación de perfiles.

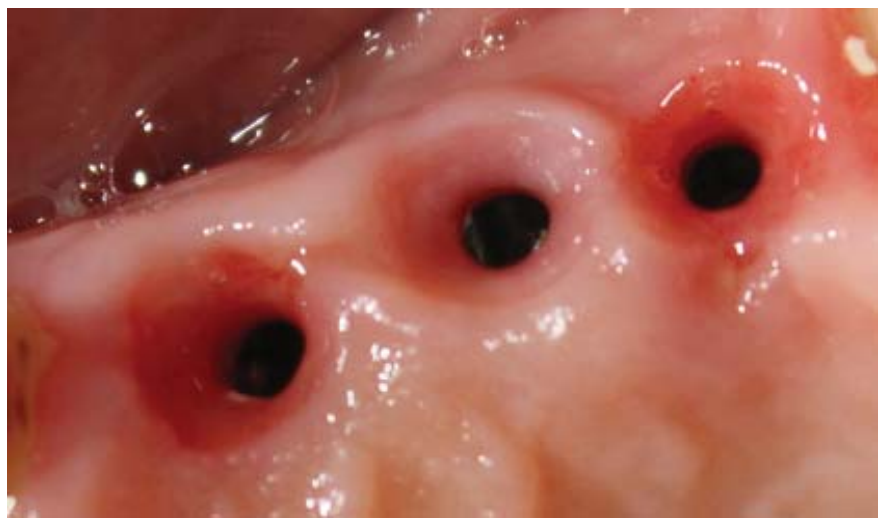

Figura 11. Control post tratamiento, se observa conformación adecuada de perfiles.
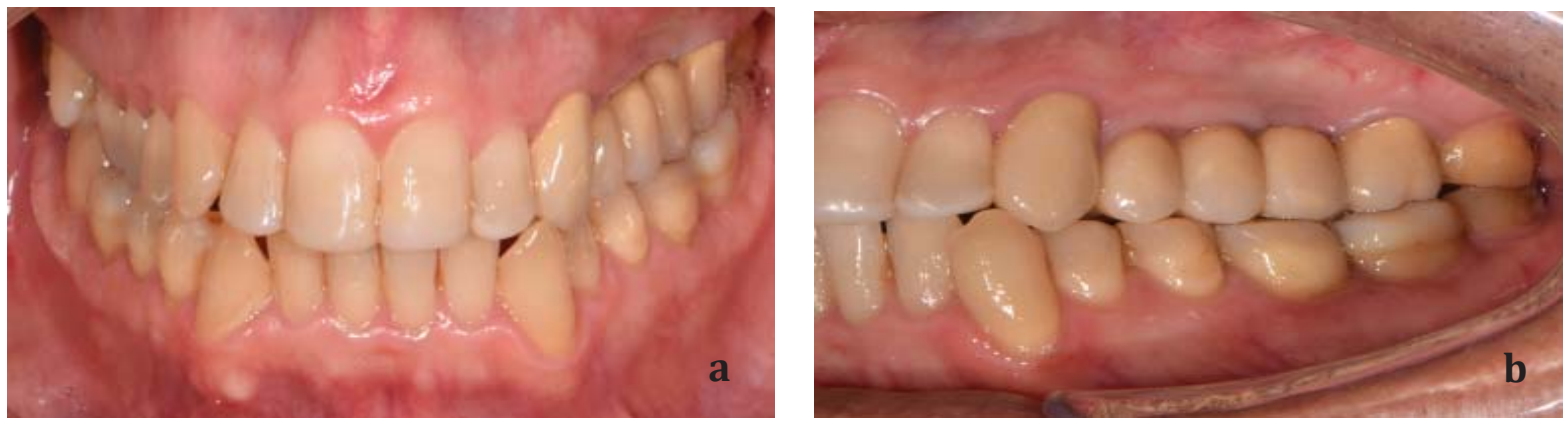

Figura 12. Restauración definitiva. (a) Vista Frontal (b) Vista lateral 


\section{DISCUSIÓN}

Los resultados estéticos de las prótesis implanto-soportadas dependen de la forma y textura de los tejidos blandos (13). El manejo de los tejidos blandos alrededor de los implantes dentales puede ser realizado antes o después de la fase quirúrgica, así como antes o después de la carga sobre el implante (14).

La utilización de polímeros para conformación de perfil de emergencia en prótesis sobre implantes, tanto en provisionales sobre implantes como en cicatrizadores personalizados, en la actualidad es de suma importancia por cuanto la capacidad de pulido de una superficie de polímero es superior a la del acrílico. Es por eso que nos resulta de gran ayuda conformar los tejidos periimplantarios sin causar daño o inflamación a los mismos. Chour et al., en un estudio publicado el 2016 indican que el acabado y pulido final de la resina es un paso crítico en el éxito del procedimiento restaurativo (15). Koutozis et al., en un estudio publicado el 2011, en el cual comparan superficies de pilares de cicatrización de Titanio versus pilares de cicatrización de polímero, llegan a la conclusión de que ninguno de los dos incrementa el riesgo de pérdida ósea marginal y recesión gingival durante el periodo de cicatrización (16). Por lo cual la conformación del tejido blando con resina es altamente aceptada como procedimiento. En el pasado, las diferencias entre el tamaño de los cicatrizadores y los dientes daban como resultado restauraciones en forma de silla de montar.

Había compromiso significativo en términos de estética y salud periodontal a largo plazo de los tejidos blandos debajo de la porción de silla de montar de la corona implanto soportada. Los cicatrizadores permiten que se desarrollen los perfiles de emergencia óptimos en las restauraciones definitivas sin la presencia de silla de montar. Estos deben ser usados con los tamaños adecuados a los dientes a ser reemplazados (17). Dado que nuestro objetivo es imitar los contornos gingivales y perfiles de emergencia óptimos utilizamos la técnica del cicatrizador personalizado ya que algunos sistemas de implantes aun cuando sus tornillos de cicatrización son divergentes no logran imitar adecuadamente los contornos de un diente natural, más específicamente de las piezas posteriores debido al diámetro que presentan. Además debemos tomar en cuenta que el contorno gingival circundante a la corona sobre implante no lo proporciona de manera independiente el pilar protésico sino también la restauración, es decir el material de la corona. El uso de pilares de cicatrización personalizados nos brinda la opción de conformar el tejido periimplantario según las dimensiones de las piezas a ser reemplazadas, dimensiones que se obtienen del protocolo de planificación previo a la fase quirúrgica (18).

\section{CONCLUSIONES}

La técnica de cicatrizadores personalizados resulta ser una buena alternativa para conformación de perfiles de emergencia mediante la técnica de compresión de los tejidos periimplantarios, esencialmente en el sector posterior, en el cual la estética no se ve afectada.

La utilización de cicatrizadores con componentes de polímeros adecuadamente adaptados pueden optimizar los procesos de conformación de perfiles de emergencia, previos a la colocación de un provisional y/o la restauración definitiva.

Esta técnica podría suplir la necesidad de la utilización de una corona provisional en el sector posterior, reduciendo significativamente el costo de un tratamiento de conformación de tejidos, ya que al utilizar incrementos de resina con un pulido prolijo reemplazamos la corona provisional.

Al sustituir a la corona provisional sobre implante también se puede lograr una impresión con transfer personalizado para copiar la conformación previa de los tejidos.

\section{Correspondencia \\ Lizzeth Fiorella Huaytalla Oré \\ E-mail: lizzeth.huaytalla@upch.pe \\ carlos.matta@upch.pe>}

\section{REFERENCIAS BIBLIOGRAFICAS}

1. Cordioli G, Brugnolo E, Lazzara RJ, Mazzocco C, Venturelli A. Osteoingrazione nella pratica clinica. 2nd ed. Quinto Vicentino: Grafiche Wanda; 1995.

2. Berglundh T, Abrahamsson I, Lang NP, Lindhe J. De novo alveolar bone formation adjacent to endosseous implants: A model study in the dog. Clin Oral Implants Res. 2003;14:251-62.

3. Schenk RK, Buser D. Osseointegration: a reality. 
Periodontol 2000. 1998;17:22-35.

4. Berglundh T, Abrahamsson I, Welander M, Lang NP, Lindhe J. Morphogenesis of the peri-implant mucosa: An experimental study in dogs. Clin Oral Implants Res. 2007;18:1-8.

5. Salvi GE, Bosshardt DD, Lang NP, et al. Temporal sequence of hard and soft tissue healing around titanium dental implants. Periodontol 2000. 2015;68:135-52.

6. Berglundh T, Lindhe J, Ericsson I, Marinelio C, Liljenberg B, Thomsen P. The soft tissue barrier at implants and teeth. Gin Oral Implant Res. 1991;2:81-90.

7. Berglundh T, Lindhe J. Dimension of the periimplant mucosa. J Clin Periodontol. 1996;23:971-3.

8. Misch C. Contemporary Implant Dentistry. 3rd ed. St. Louis:Mosby;1993.

9. Mattias I, Rocha S, Molinari A, Hermann C, Thomé G. Intermediários para Implantes Cone Morse: Seleção e utilização. J do Ilapeo. 2008;2:96-104.

10. Pow EHN, McMillan AS. A modified implant healing abutment to optimize soft tissue contours: A case report. Implant Dent. 2004;13:297-300.

11. Parpaiola A, Sbricoli L, Guazzo R, Bressan E, Lops D. Managing the peri-implant mucosa: A clinically reliable method for optimizing soft tissue contours and emergence profile. J Esthet Restor Dent. 2013;25:317-23.

12. Shor A, Schuler R, Goto Y. Indirect implant-supported fixed provisional restoration in the esthetic zone: Fab- rication technique and treatment workflow. J Esthet Restor Dent. 2008;20:82-95.

13. Grunder U, Gracis S, Capelli M. Influence of the 3-D bone-to-implant relationship on esthetics. Int J Periodontics Restorative Dent. 2005;25:113-9.

14. Strub J, Gaberthüel T, Grunder U. The role of attached gingiva in the health of peri-implant tissue in dogs 1: clinical findings. Int J Periodontics Restor Dent. 1991;11:317-33.

15. Chour R, Moda A, Arora A, Arafath M, Shetty V, Rishal Y. Comparative evaluation of effect of different polishing systems on surface roughness of composite resin: An in vitro study. J Int Soc Prev Community Dent. 2016;6(Suppl 2):S166-70. doi: 10.4103/22310762.189761

16. Koutouzis T, Richardson J, Lundgren T. Comparative soft and hard tissue responses to titanium and polymer healing abutments. J Oral Implantol. 2011;37:174-82.

17. Drago C. Implant restorations : A step-by-step guide for dentists. 2nd ed. UK: Blackwell Munksgaard; 1997.

18. Velásquez D, Yaneth J, Kaliks J. Comparison of direct and indirect techniques to develop customized implant impression copings: A pilot study. Int J Periodontics Restorative Dent. 2015;35:525-31.

Recibido: 10-07-2018

Aceptado: 23-11-2018 